\title{
A Complex Adaptive Systems View of Digital Ecodynamics for Business Performance among Manufacturing SMEs
}

\author{
Ana Ortiz de Guinea \\ HEC Montréal \\ ana.ortiz-de-guinea@hec.ca
}

\author{
Louis Raymond \\ Université du Québec à Trois-Rivières \\ louis.raymond@uqtr.ca
}

\begin{abstract}
Taking a complex adaptive systems approach, this paper investigates the different configurations of digital ecodynamics - IT capabilities, dynamic capabilities, and environmental conditions - associated to high levels of business performance in manufacturing SMEs. Results from a fuzzy-set qualitative comparative analysis (fSQCA) of 126 manufacturing SMEs show that, as expected from our theoretical development, these firms attain high business performance when they dispose of at least one IT capability and one dynamic capability. More specifically, IT capabilities for innovation and flexibility along with dynamic capabilities for coordination and integration are necessary for high business performance since they appear in all high-performing configurations. Our study contributes to information systems research by taking a holistic approach to the IT capability-performance link in the specific context of SMEs.
\end{abstract}

\section{Introduction}

The study of the relation between information technology (IT) capabilities and business performance represents one of the core research streams of the information systems (IS) field. Thus, research on the 'IT-business value' issue has been quite productive and has identified different IT capabilities, dynamic capabilities, and environmental conditions as factors influencing business performance $\left[\begin{array}{ll}1, & 2\end{array}\right]$. Notwithstanding its important contributions to our understanding of how IT capabilities may help firms attain higher levels of performance, this literature can be problematized to identify remaining issues worth addressing [3].

First, although the literature has identified IT capabilities and dynamic capabilities as facilitators of business performance, most studies have investigated each type of capability independently, as recent reviews critically note [1]. This ignores the potentially complex interplay between IT capabilities and dynamic capabilities in enabling business performance. Thus, there is a need to study IT and dynamic capabilities holistically [4, 5].

Second, most studies take a 'variance' approach that assumes 'unifinality', i.e. that assume there is only one way for business performance to occur (through each of the independently identified factors) [6]. However, assuming that an outcome results from single factors seems at odds with reality [7], whereas firms appear to achieve performance from many different starting positions and through many different paths (i.e., 'equifinality') [8]. Thus, there are current calls for research to take a more complex approach capable of allowing for equifinality such a 'configurational' approach $[1,9]$.

Third, most research dealing with IT capabilities and business performance has been conducted among large enterprises [e.g., 10]. This is worrisome for two main reasons. The first is that findings from large firms might not be generalizable to small and medium-sized enterprises (SMEs), as research has shown that organizational size influences organizational performance [11]. The second reason is that, SMEs are paramount for the economy [12]. In the European Union and the U.S., they represent around 99\% of all firms and account for more than $60 \%$ of all jobs [1]. As a result, there are recent calls for research on IT capabilities in the specific context of SMEs $[4,12]$.

To address these three issues, this study seeks to describe and explain the way in which IT capabilities (i.e., IT capabilities for innovation, flexibility, and integration), dynamic capabilities (i.e., sensing, learning, coordination, and integration), and the manufacturing or environmental context (i.e., firm size and environmental uncertainty) interact to enable business performance. Consistent with past literature, we use the term digital ecodynamics to refer to the interplay between IT capabilities, dynamic capabilities, and the environmental context [5]. In addition, we study digital ecodynamics and business performance from a complex adaptive systems approach that allows for complexity and equifinality [13, 14]. Therefore, our exploratory research questions are as follows: What are 
the digital ecodynamic configurations that lead to high business performance in manufacturing SMEs? And what are the configurations that prevent these firms from attaining such high performance?

\section{A Complex Adaptive Systems Approach to Digital Ecodynamics}

From a complex adaptive systems approach, we seek to identify the different configurations of digital ecodynamic elements that attain (and do not attain) business performance. A configuration is a specific combination of causal elements or conditions (in our case, IT capabilities, dynamic capabilities, and the manufacturing context) that together generate the outcome of interest (in our case, business performance) $[5,15,16]$. The basic idea is that there should be different ways of configuring digital ecodynamic elements that equally lead to high business performance. This reasoning leads to a conceptual framework based on complex adaptive systems (Figure 1), further explained in the following sections $[13,17]$.

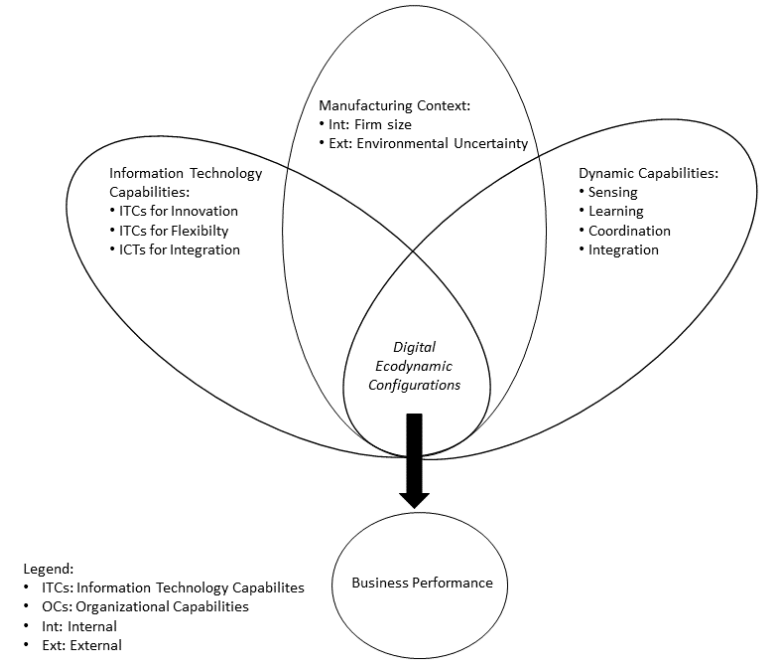

Figure 1: Configuration model of manufacturing IT alignment for business performance

\subsection{Digital Ecodynamics and Business Performance}

Our objective is to identify different configurations of digital ecodynamics capable of achieving business performance. Business performance, our outcome of interest, refers to a firm's growth and profitability relative to its competitors [18]. Thus, business performance includes a firm's market share and sales, as well as its financial returns compared to those of competitors [18].
Digital ecodynamics refer to the complex ways in which dynamic capabilities, IT capabilities, and the manufacturing or environmental context of firms may interact as these conditions affect business performance $[4,5]$. The first condition or element of the firm's digital ecodynamics is its IT capabilities. IT capabilities encompass both tangible and intangible elements such as the firm's IT infrastructure and IT competencies [19]. Building upon earlier research, we define three types of IT capabilities: IT capabilities for innovation, IT capabilities for flexibility, and IT capabilities for integration [20, 21]. IT capabilities for innovation allow manufacturing firms to experiment with new ideas and as such, encompass technologies such as computeraided design (CAD) that are employed to develop new products and services [21]. IT capabilities for flexibility allow firms to adapt their manufacturing processes and regroup technologies such as automatic handling or computer numerical control (CNC) [21]. Finally, IT capabilities for integration are those aimed at exploiting a firm's know-how for efficiency gains, and thus include technologies that help with integration and coordination, such as ERP and CRM [21].

Dynamic capabilities, the second element of the organization's digital ecodynamics, refer to the ability of firms to adapt to the business environment [1,22, 23]. As such, these capabilities represent evolutionary responses to the complex environment in which most manufacturing firms operate at present [22]. Dynamic capabilities entail sensing and learning as well as coordinating and integrating [24]. Sensing is the capability to scan the environment for opportunities and threats, while learning is the capability to identify, assimilate, and apply knowledge to develop new products and services [24]. Coordinating capabilities refer to work output synchronicity and expertise compatibility between group whereas integrating capabilities refer to the capacity to synchronize and adapt work processes changing situations [24].

Finally, the manufacturing (or environmental) context includes elements thar are internal or external to the firm. The external context is characterized by environmental uncertainty and it includes dynamism the rate and unpredictability of environmental change as well as heterogeneity - the variety of the competitive landscape $[25,26]$. Now, firm size may be considered as a proxy for the internal context since research has consistently shown that organizational size influences business performance [11, 27].

\subsection{Complex Adaptive Systems}

Stemming from 'open systems' thinking, a complex adaptive systems (CAS) approach entails viewing the components of the firm's digital ecodynamics as 
forming multivariate interdependency patterns $[14,17$, 28]. Such an approach implies that an outcome, such as business performance results from internal congruency of the elements forming the organizational system, that is, the elements of the firm's digital ecodynamics in this case (i.e., IT capabilities, dynamic capabilities, and manufacturing context) $[14,17,29]$. The idea is that these three components form a complex system or organized whole in which the elements are interdependent and interact in multiple and nonlinear ways in reaching an outcome $[17,28,30]$. In contrast to variance approaches like SEM in which the goal is to make predictions about the net effects of each digital ecodynamic component [31], the CAS approach does not focus on individual components. Indeed, an individual component might appear to behave randomly if examined in isolation from the other components of the system. As a result, the CAS approach is holistic, viewing the system as a whole in order to identify elemental patterns or configurations [13, 32]. This approach thus implies holistic interconnectedness and mutual causality among digital ecodynamic components $[13,17,33]$.

In addition, CAS allow for 'equifinality' [14, 17], which means that the same outcome can be reached in different ways and from different starting positions [6, 30]. Equifinality allows for different configurations of the elements forming the digital ecodynamics to reach the same level of business performance and stands in sharp contrast to the unifinality assumption of variance approaches [6, 34].

A related and final characteristic of CAS is 'causal asymmetry', which allows equifinal configurations to vary across different levels of the outcome [4, 6]. In other words, different equifinal configurations of digital ecodynamics might lead to high business performance, other configurations might lead to average performance, and yet others to low performance. Causal asymmetry also represents a departure from variance approaches that assume causal symmetry. In causal symmetry, the same factors are assumed to lead to the existence and the absence of the outcome since correlations are intrinsically symmetric. For instance, if one was to model the inverse of business performance, the result would be unchanged except for the signs of the correlation coefficients [6].

In summary, we take a CAS approach to examine manufacturing SMEs' digital ecodynamics for business performance by allowing interdependence, nonlinearity, and causal asymmetry $[30,33]$. Such approach has been argued to better align with the complex reality of today's organizations [7]. In doing so, we seek to uncover the different digital ecodynamic configurations of IT capabilities (i.e., IT capabilities for innovation, IT capabilities for flexibility, and IT capabilities for integration), dynamic capabilities (i.e., learning, sensing, coordinating, and integrating), and the manufacturing context (i.e., environmental uncertainty and firm size) associated to high levels of business performance.

\subsection{Digital Ecodynamic Configurations for High Business Performance}

Given the absence of empirical studies attempting to integrate the different components of the firm's digital ecodynamics, we first provide theoretical arguments for certain general expectations with regard to digital ecodynamics configurations associated a priori to high business performance. More specifically, we expect that such configurations will show at least one type of IT capabilities, be it IT capabilities for innovation, IT capabilities for flexibility or IT capabilities for integration, and at least one dynamic capability, be it the sensing, learning, coordination or integration capability.

The previous statement implies that at least one of the IT capabilities and one of the dynamic capabilities included herein are 'necessary' in a configuration associated to high business performance. With regards to IT capabilities, the IT-business value literature has argued that these capabilities operate in conjunction with other organizational and dynamic capabilities. Thus value is generated from the unique orchestration of capabilities belonging to the two realms technological and organizational [1]. As a result, at least one of IT capabilities for innovation, flexibility or integration will need to be present in high-performing configurations. Now, firms increase their repertoire of responses to fit environmental conditions by acquiring, developing and utilizing different types of IT applications, [35, 36, 37]. For example, IT capabilities for innovation include interactive CAD systems that, apart from generating designs with repetitive accuracy, allow for easy design modifications to satisfy customers' evolving preferences [38]. Such applications allow for exploration [4] and thus, for quick adaptions to market changes $[39,40]$. Likewise, IT capabilities for flexibility - enabled by advanced manufacturing technologies such as computer numerical control (CNC), computer aided maintenance (CAM), automated handling, and applications for logistics and optimization [41] - serve to adjust internal and external processes for production and distribution. For example, while CAM includes software systems that streamline planning, scheduling and maintenance so that time-outperiods are avoided, CNC allows for the automatic control of manufacturing tools via computer systems which makes the manufacturing process more flexible, precise and efficient. Likewise, automated handling creates value for the organization via a flexible 
management and control of inventory, while applications for logistics and optimizing also influence organizational agility by providing a better and more flexible management of the manufacturing operations of a given firm, thus supporting organizational agility [39]. Finally, IT for integration which encompassing enterprise systems (ES), such as ERP and CRM, improve integration and enable distributed operations and collaboration [42]. ES allow for three different types of integration that facilitate firms' adaptability to environmental conditions: vertical (i.e., between different hierarchical levels), horizontal (i.e., between departments or functions within an organization), and technical (i.e., between different systems in order to be compatible with each other) [43]. Such integration results in a more efficient collaboration and faster decision-making across functional units by breaking traditional 'silos' [44]. Consistent with this idea, past research has shown that, large organizations that have implemented ERP, when faced with environmental changes, often look for a response among the pre-built business processes embedded into the ERP [45]. Additionally, the disposition of add-ons in such systems which have special functionalities enable different capabilities that firms may apply to search for the best responses to changes in their business environment [45].

The second necessary realm for the evolutionary orchestration of resources are dynamic capabilities [5, 46]. A first such capability, sensing, allows firms to scan the environment while a second one, learning, enables firms to avoid rigidities and obsolescence [47]. Now, IT capabilities such as IT for integration might complement and enhance sensing and learning capabilities. For example, in a typical CRM system, the system's analytical component is used to analyze the data gathered by the operational component, also including web traffic analysis, sentiment analysis of social media postings and text analytics of customers' reviews to identify demand trends [48, 49]. Thus, IT capabilities might enhance the extent to which firms can generate insights or gather further knowledge of their markets [50]. In addition, coordination and integration are dynamic capabilities that allow firms to gain returns on their know-how [47]. These last two capabilities, when coupled with IT capabilities for innovation and flexibility, can lead to incremental innovations in the form of modified products or services. Such incremental improvements are geared towards lowering costs and maximizing efficiency by exploiting existing knowledge [51]. In summary, we expect that any configuration capable of reaching high business

\footnotetext{
${ }^{1}$ Sistema de Análsis de Balances Ibéricos (System of Iberian Balance
} Sheet Analysis; SABI) performance will contain at least one type of IT capabilities (i.e., IT capabilities for innovation, IT capabilities for flexibility, and IT capabilities for integration) and one dynamic capability (i.e., sensing, learning, coordination, and integration).

\section{Methodology}

A questionnaire-based survey methodology was employed to gather data on the constructs of interest among Spanish manufacturing SMEs. The questionnaire was answered by a manager who had sufficient knowledge of the firm's IT applications, manufacturing operations and business performance, such as the firm's IT, operations, and finance manager. A total of 126 manufacturing firms completed the questionnaire, with a response rate of approximately $10 \%$. The sampled firms have been operating for an average of 34 years, with a minimum of 4 years and a maximum of 49. The SMEs composing the sample have between 50 and 250 employees, with an average of 100 . They belong to various high-knowledge sectors, such as the manufacturing of metal products, electrical equipment, and machinery.

The research constructs were measured on the basis of the extant literature on IT and dynamic capabilities and on SME management. For IT capabilities, we followed previous research $[4,21]$, and asked respondents whether different IT capabilities for innovation, for flexibility, and for integration where in place in their firm. For dynamic capabilities the measure of Pavlou and El Sawy [24] was employed with 5-point Likert scales. More precisely, sensing was captured with 2 items, learning with 4, and coordination and integration with 3 each. Environmental uncertainty, a reflection of the external manufacturing context, was measured with seven items capturing heterogeneity and dynamism [25]. Firm size, an indicator of the internal manufacturing context, was extracted from a database containing information on Spanish firms, including those forming the sample ${ }^{1}$. Finally, we took an approach based on 'subjective' measurement often used in the context of SMEs [18] to assess the outcome of interest, namely the business performance construct. In using such an approach, this last research construct was measured by asking respondents to evaluate their firm's performance through their perceptions of the firm's profitability and sales growth relative to the competition for the last five years [18] (8 five-point scales: $1=$ much below average, ..., $5=$ much above average). ${ }^{2}$ All items are available upon request.

\footnotetext{
${ }^{2}$ Note that this last measure was found to have a level of internal consistency adequate for its use as the outcome variable in a fsQCA analysis $(\alpha=0.92)$.
} 


\begin{tabular}{|c|c|c|c|c|c|c|c|c|}
\hline \multirow[b]{2}{*}{ Research Variable } & \multirow[b]{2}{*}{$\alpha^{a}$} & \multirow[b]{2}{*}{ mean } & \multirow[b]{2}{*}{ stdev } & \multirow[b]{2}{*}{$\min$} & \multirow[b]{2}{*}{$\max$} & \multicolumn{3}{|c|}{ fuzzy set calibrations } \\
\hline & & & & & & fully in & crossover & fully out \\
\hline Environmental Uncertainty & 0.84 & 2.6 & 0.7 & 1.0 & 4.7 & 3.0 & 2.6 & 2.1 \\
\hline Organizational Size & - & 140 & 140 & 15 & 1000 & 145 & 99 & 74 \\
\hline Sensing Capability & 0.80 & 3.3 & 1.1 & 1.0 & 5.0 & 3.8 & 3.3 & 2.3 \\
\hline Learning Capability & 0.91 & 3.2 & 1.0 & 1.0 & 5.0 & 3.8 & 3.3 & 2.3 \\
\hline Coordination Capability & 0.87 & 3.7 & 0.8 & 1.7 & 5.0 & 4.5 & 3.7 & 3.2 \\
\hline Integration Capability & 0.85 & 3.7 & 0.9 & 1.0 & 5.0 & 3.9 & 3.5 & 2.7 \\
\hline IT Capability for Innovation & - & 1.3 & 1.1 & 0 & 3 & 2.5 & 0.5 & 0.0 \\
\hline IT Capability for Flexibility & - & 2.0 & 1.2 & 0 & 4 & 2.5 & 1.5 & 0.5 \\
\hline IT Capability for Integration & - & 3.8 & 0.9 & 1 & 5 & 4.5 & 3.5 & 2.5 \\
\hline Business Performance & 0.92 & 3.8 & 0.8 & 1.0 & 5.0 & 3.6 & 3.1 & 2.7 \\
\hline
\end{tabular}

Table 1. Reliability, descriptive statistics and fuzzy set calibration of the research variables

We investigated our CAS model using fuzzy set qualitative comparative analysis (fsQCA), a secondgeneration configurational analysis technique [56]. This technique was initially developed to deal with small sample sizes, but it is also able to deal with large--sized samples (100 cases or more) [56, 40]. Consistent with configurational theory, fsQCA allows for equifinality [6]. In a nutshell, fsQCA is an analytical technique that uses Boolean algebra for determining the different configurations of elements that generate the same outcome $[40,55]$. In this technique each element is considered a fuzzy set. Fuzzy sets have different degrees of membership into the set: fully in, fully out, and crossover [40]. Thus, following fsQCA recommendations [57], we used direct calibration of the raw data by identifying the three points of membership based on the scale (or index) values].

The configurational analysis begins with the creation of a truth table of $2^{k}$ rows with a list of all possible configurations, with $k$ representing the number of individual elements. The truth table is then sorted based on frequency and consistency. While frequency represents the number of observations for each possible configuration, consistency describes "the degree to which cases correspond to the set-theoretic relationships expressed in a solution" [6, p. 402]. For samples smaller than 150 cases, the recommendation is to set the frequency threshold at 2 [54]. As a result, the frequency threshold was set here at 2 and thus, all configurations with a smaller frequency were removed for further analysis. Furthermore, the recommended threshold of 0.75 for consistency was also used [54]. For configurations above the consistency threshold, the outcome variable was set at 1 (because these configurations are the ones that fully explain the outcome) and for the rest was set at 0 . The fsQCA software then computes three sets of solutions: complex, parsimonious, and intermediate. While the complex solution represents all possible configurations of conditions when traditional logical operations are applied, the interpretation of the resulting configurations is difficult and often impractical. The complex solution is thus further simplified into parsimonious and intermediate solutions. The parsimonious solution yields the most important conditions, called 'core' conditions or elements, which cannot be left out from any configuration [6]. Core elements are those for which the evidence for a causal relationship with the outcome is strong [6]. The intermediate solution is obtained through the performance of counterfactual analysis on the complex and parsimonious solutions. The intermediate solution includes the parsimonious solution and is part of the complex solution. As a result, the conditions that are not part of the parsimonious solution but are part of the intermediate solution are called 'peripheral' conditions or elements [6]. Peripheral elements are those for which the evidence indicates a weak causal relationship with the outcome. The recommendation is to use a combination of the parsimonious and intermediate solutions for interpreting fsQCA results [54]. More specifically, the researcher should identify the conditions of the parsimonious solution in the intermediate solution so that a table can be created that includes both core and peripheral elements [6]. This results in a combined solution that presents core and peripheral elements and helps in the interpretation of the resulting configurations.

\section{Results}


The research variables' reliability and descriptive statistics are presented in Table 1. Note that IT capabilities for innovation, flexibility, and integration are 'index' rather than 'scale' measures [53]. An index variable tends to follow a Poisson-type rather than a normal distribution, that is, to be right-skewed if the mean is small. Moreover, an index regroups elements not expected to be highly intercorrelated, hence the inappropriateness of Cronbach's $\alpha$ coefficient to test its reliability [54].

\subsection{Necessity analysis}

Usually, the first step in fsQCA analysis is the study of necessary conditions (or elements). A condition is necessary when its consistency score is above 0.9 [52]. Consistency can be defined as extent to which members in a condition also show membership in the outcome [58]. As it is shown in Table 2, consistency scores indicate that no digital ecodynamic condition alone is necessary for the attainment of high levels of business performance in manufacturing SMEs.

\subsection{Sufficiency Analysis}

The major analytical contribution of fsQCA resides in its ability to evaluate relations between configurations (that is, combinations of conditions) and the outcome(s) $[40,55]$. Sufficiency analysis entails such evaluation and it is usually the second step in fsQCA analysis [53]. Table 3 shows the results of the fsQCA analysis with the causal configurations for the presence and absence (indicated by ' $\sim$ ') of high business performance ${ }^{3}$. Please note that Table 3 uses the notation introduced by Ragin [54]: black circles represent the presence of a condition, circles with a cross-out indicate the absence of the condition, large circles represent core conditions, small circles represent peripheral ones and blank spaces represent an immaterial condition (or a situation characterized by a "do not care" in which one condition may be either present or absent without altering the outcome).

With respect to the presence of the outcome, the analysis yields three equifinal digital ecodynamic configurations leading to high business performance. The raw coverage ${ }^{4}$ is between .128 and .136 , the unique coverage $^{5}$ is between .038 and .048, and the consistency $^{6}$ values for all the configurations are above

\footnotetext{
${ }^{3}$ The calibration for high business performance is as follows: 3.6 for full membership, 3.1 as the cross-over point, and 2.7 as the threshold for nonmembership.

${ }^{4}$ The proportion of cases (in terms of fuzzy membership value) that can be described by the configuration [40].
}

.81. According to Ragin [55] a consistency score below .75 indicates substantial inconsistency, which is not the case here. Finally, the overall solution consistency is .823 and the overall solution coverage ${ }^{7}$ is .250 . Consistent with our expectation, each of the three digital ecodymamic configurations capable of attaining high business performance contain at least one type of IT capabilities and at least one of the dynamic capabilities.

\begin{tabular}{|l|c|c|}
\hline \multirow{2}{*}{ Config. element } & \multicolumn{2}{|c|}{ High Business Performance } \\
\cline { 2 - 3 } & Consistency & Coverage \\
\hline Env. Uncertainty & 0.519 & 0.538 \\
\hline Org. Size & 0.518 & 0.538 \\
\hline Sensing & 0.698 & 0.638 \\
\hline Learning & 0.656 & 0.628 \\
\hline Coordination & 0.643 & 0.651 \\
\hline Integration & 0.752 & 0.606 \\
\hline IT for Innovation & 0.684 & 0.569 \\
\hline IT for Flexibility & 0.738 & 0.599 \\
\hline IT for Integration & 0.736 & 0.606 \\
\hline
\end{tabular}

\section{Table 2. Analysis of necessary elements}

The first configuration (HP1) is characterized by SMEs with smaller sizes and operating in a manufacturing context lacking environmental uncertainty, with all three types of IT capabilities, as well as coordinating and integration capabilities. Likewise, the second digital ecodynamic configuration (HP2) is characterized by a lack of environmental uncertainty, but in this configuration, all IT capabilities and dynamic capabilities need to be present. The third configuration (HP3) is formed by smaller firms facing uncertain environments that dispose of all dynamic capabilities as well as IT capabilities for innovation and flexibility, but that lack IT capabilities for integration. Finally, Table 3 also shows another three configurations that are equifinal in attaining low or no business performance (NHP1, NHP2, and NHP3), which show asymmetry in causality.

Finally, it is important to note that, notwithstanding the prior analysis of necessary conditions, the coordination capability, the integration capability, and IT capabilities for innovation and for flexibility appear to be necessary conditions for high business performance. This is because each of these capabilities is present in all three high-performing configurations.

\footnotetext{
${ }^{5}$ The proportion of cases (in terms of fuzzy membership value) that can be described by a configuration appearing in a solution set but cannot be described by any other configuration from the set [40].

${ }^{6}$ The extent to which a given combination is a sufficient condition for the outcome [58].

${ }^{7}$ The proportion of cases (in terms of fuzzy membership value) that can be described by at least one configuration in a solution set [40].
} 


\begin{tabular}{|c|c|c|c|c|c|c|}
\hline \multirow{2}{*}{$\begin{array}{c}\text { Configuration } \\
\text { Configurational element }\end{array}$} & \multicolumn{3}{|c|}{ High Business Performance } & \multicolumn{3}{|c|}{ High Business Performance } \\
\hline & HP1 & HP2 & HP3 & NHP1 & NHP2 & NHP3 \\
\hline \multicolumn{7}{|l|}{ Manufacturing Context } \\
\hline $\begin{array}{l}\text { Environmental Uncertainty } \\
\text { Organizational Size }\end{array}$ & $\bigotimes$ & $\bigotimes$ & $\otimes$ & $\otimes$ & 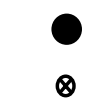 & 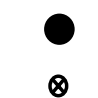 \\
\hline \multicolumn{7}{|l|}{ Dynamic Capabilities } \\
\hline $\begin{array}{l}\text { Sensing Capability } \\
\text { Learning Capability } \\
\text { Coordination Capability } \\
\text { Integration Capability }\end{array}$ & & $\begin{array}{l}0 \\
\bullet \\
\bullet\end{array}$ & $\begin{array}{l}0 \\
\bullet \\
\bullet\end{array}$ & $\otimes$ & & $\begin{array}{l}\otimes \\
\otimes\end{array}$ \\
\hline \multicolumn{7}{|l|}{ Manufacturing IT Capabilities } \\
\hline $\begin{array}{l}\text { IT capability for Innovation } \\
\text { IT Capability for Flexibility } \\
\text { IT Capability for Integration }\end{array}$ & & 0 & 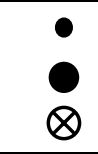 & $\otimes$ & 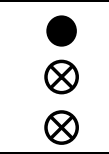 & 0 \\
\hline \multicolumn{7}{|l|}{ Conditions tested } \\
\hline Consistency & 0.840 & 0.856 & 0.811 & 0.748 & 0.787 & 0.927 \\
\hline Raw coverage & 0.128 & 0.136 & 0.067 & 0.167 & 0.136 & 0.132 \\
\hline Unique coverage & 0.038 & 0.047 & 0.041 & 0.117 & 0.077 & 0.088 \\
\hline Overall solution consistency & & 0.823 & & & 0.791 & \\
\hline Overall solution coverage & & 0.215 & & & 0.346 & \\
\hline
\end{tabular}

Legend. $:$ : presence of a core condition $\quad \bullet$ presence of a peripheral condition $\bigotimes$ : absence of a core condition $\otimes$ : absence of a peripheral condition blank: immaterial condition ("don't care")

Table 3. Causal configurations for the presence and absence $(\sim)$ of high performance

configurations for high business performance [55]. ${ }^{8}$

\section{Discussion}

The purpose of this exploratory research was to identify the digital ecodynamic configurations that enable manufacturing SMEs to attain high business performance. In doing so from a CAS view, this study's findings contribute to the literature by answering recent calls for the investigation of the interplay between IT capabilities and dynamic capabilities in relation to business performance from complex and configurational approaches $[1,5]$. Our results suggest that dynamic capabilities for coordination and integration as well as IT capabilities

\footnotetext{
${ }^{8}$ With the recommended consistency threshold of 0.90 for identifying necessary conditions employed in the necessity analysis (see Table 2), it is possible that fsQCA fails to identify single necessary conditions, and thus, a false negative or type II error may occur [55]. Relaxing this threshold, however, can result in identifying conditions that may not
}

for innovation and flexibility are necessary in this regard.

In addition, since prior studies have mostly concentrated on intangible and abstract representations of IT capabilities [e.g., 56], the present study also contributes by answering recent calls for research into the identification of concrete and specific IT capabilities that, along with other organizational capabilities and dynamic capabilities, enable performance outcomes $[1,4]$. Identifying capabilities that refer to specific and concrete technologies is of high practical relevance [1]. For instance, our results demonstrate that capabilities stemming from specific technologies (e.g., CAD/CAM, rapid prototyping, ERP) along with coordination and integration capabilities offers manufacturing SME managers

be actually necessary, thus producing false positives or type I errors [55]. As a result, a second approach that might produce fewer false negatives and positives is to identify single necessary conditions by selecting the conditions that are present in all configurations [55]. 
practical ways to emulate larger firms in meeting the challenges of Industry 4.0. Contributing to practice is also important for the IS research field, since it is likely to increase its relevancy $[57,58,59]$.

Moreover, we note at this juncture that our study falls within the paradigm shift in the IS field advocated by Merali et al. [33]. Such paradigm shift calls for approaching information systems as CAS grounded in both complexity and configurational theory, especially given the present dynamism and uncertainty of the manufacturing SMEs' business environment [60]. Now, complexity theory, configurational theory, and its corresponding methodologies (such as fsQCA) have three overarching characteristics that have been adopted in this study: a) holistic interconnectedness and mutual causality among system elements, b) equifinality and multiple realities, and c) nonlinearities or causal asymmetry [60]. Thus, our study fits well with recent arguments for studying organizational performance from a holistic perspective grounded in complexity and configurational theory by identifying the technological, organizational, and environmental factors that enable high performance among firms [60].

Finally, as in any research endeavor, this study has certain limitations that warrant future research. First, our sample consisted mostly of manufacturing SMEs operating in high-knowledge and technology-oriented sectors (e.g., machinery and equipment manufacturing). As there is great heterogeneity among SMEs with regards to their sector of activity and the markets in which they operate, future research could focus on exploring strategic fit patterns of organizational and IT capabilities in industries with varying degrees of knowledge requirements and technical intensity. Furthermore, different strategic orientations regarding the firm's general focus as well as its view of IT, could be explored along with digital ecodynamic concepts to provide more insight into the different ways in which SMEs may attain (and may not attain) high levels of competitive performance.

\section{Conclusion}

In summary, a CAS approach allowed us to identify the causal configurations that associate the digital ecodynamics of manufacturing SMEs to high levels of business performance. The results indicate that SMEs with IT capabilities for innovation, IT capabilities for flexibility along with dynamic capabilities for coordination and integration are able to attain such performance.

\section{Acknowledgments}

This research was supported by a grant from the Program "Retos de la Sociedad" of the Ministry of Economy, Industry, and Competitiveness the Government of Spain (ECO2017-88924R).

\section{References}

[1] Steininger, D., P. Mikalef, A. Patelli, and A. Ortiz de Guinea, "Dynamic Capabilities in Information Systems Research: A Critical Review, Synthesis and Recommendations for Future Research", Journal of the Association for Information Systems, forthcoming. [2] Schryen, G., "Revisting IS business value research. What we already know, what we still need to know, and how we can get there", European Journal of Information Systems 22(2), 2013, pp. 139-169.

[3] Alvesson, M., and J. Sandberg, "Generating Research Questions Through Problematization", Academy of Management Review 36, 2011, pp. 247271.

[4] Ortiz de Guinea, A., and L. Raymond, "Enabling innovation in the face of uncertainty through IT ambidexterity: A fuzzy set qualitative comparative analysis of industrial service SMEs", International Journal of Information Management 50, 2020, pp. 244-260.

[5] El Sawy, O.A., A. Malhotra, Y.K. Park, and P.A. Pavlou, "Seeking the configutrations of digital ecodynamics: It takes three to tango", Information Systems Research 21, 2010, pp. 835-848.

[6] Fiss, P., "Building better causal theories: A fuzzy set approach to typologies in organization research.", Academy of Management Journal 54(2), 2011, pp. 393-420.

[7] Woodside, A.G., "Moving beyond multiple regression analysis to algorithms: Calling for adoption of a paradigm shift from symmetric to asymmetric thinking in data analysis and crafting theory", Journal of Business Research 66(4), 2013, pp. 463-472.

[8] Gresov, C., and R. Drazin, "Equifinality: Functional equivalence in organizational design.", Academy of Management Review 22, 1997, pp. 403428.

[9] Wilden, R., T.M. Devinney, and G.R. Dowling, "The architecture of dynamic capability research: Identifying the building blocks of a configurational approach", The Academy of Management Annals 10(1), 2016, pp. 997-1076.

[10] Mithas, S., and R.T. Rust, "How Information Technology strategy and investments influence firm performance: Conjecture and empirical evidence", MIS Quarterly 40(1), 2016, pp. 223-245.

[11] Hong, S., and L. Oxley, "Why firm size matters: Investigating the drivers of innovation and economic 
performance in New Zealand using the Business Operations Survey", Applied Economics 48(55), 2016, pp. 1-17.

[12] Street, C., B. Gallupe, and J. Baker, "Strategic alignment in SMEs: Strengthening theoretical foundations", Communications of the Association for Information Systems 40, 2017, Article 20.

[13] Lansing, J.S., "Complex adaptive systems", Annual review of anthropology 32(1), 2003, pp. 183204.

[14] Tanriverdi, H., A. Rai, and N. Venkatraman, "Reframing the dominant quests of information systems strategy research for complex adaptive business systems", Information Systems Research 21(4), 2010, pp. 822-834.

[15] Furnari, S., D. Crilly, V.F. Misangyi, T. Greckhamer, P.C. Fiss, and R. Aguilera, "Capturing causal complexity: Heuristics for configurational theorizing", Academy of Management Review(ja), 2020.

[16] Ragin, C.C., Fuzzy-set social science, University of Chicago Press, 2000.

[17] Miller, D., "Toward a new contingency approach: The search for organizational gestalts", Journal of management studies 18(1), 1981, pp. 1-26.

[18] Croteau, A.-M., and L. Raymond, "Performance outcomes of strategic and IT competencies alignment", Journal of Information Technology 19(3), 2004, pp. 178-190.

[19] Ajamieh, A., J. Benitez, J. Braojos, and C. Gelhard, "IT infrastructure and competitive aggressiveness in explaining and predicting performance", Journal of business research 69(10), 2016, pp. 4667-4674.

[20] Hoon Yang, K., S.M. Lee, and S.-G. Lee, "Adoption of information and communication technology: impact of technology types, organization resources and management style", Industrial Management \& Data Systems 107(9), 2007, pp. 1257 1275.

[21] Uwizeyemungu, S., L. Raymond, P. Poba-Nzaou, and J. St-Pierre, "The complementarity of IT and HRM capabilities for competitive performance: a configurational analysis of manufacturing and industrial service SMEs", Enterprise Information Systems 12(10), 2018, pp. 1336-1358.

[22] Teece, D.J., "The foundations of enterprise performance: dynamic and ordinary capabilities in an (economic) theory of firms", The Academy of Management Perspectives 28(4), 2014, pp. 328-352.

[23] Eisenhardt, K.M., and J.A. Martin, "Dynamic Capabilities: What Are They?", Strategic Management Journal 21(10-11), 2000, pp. 11051121.
[24] Pavlou, P.A., and O.A. El Sawy, "The 'third hand': IT-enabled competitive advantage in turbulence through improvisational capabilities", Information Systems Research 21(3), 2010, pp. 443471.

[25] Mikalef, P., and A. Pateli, "Information technology-enabled dynamic capabilities and their effect on competitive performance: Findings from PLS-SEM and fsQCA", Journal of Business Research 70, 2017, pp. 1-16.

[26] Newkirk, H.E., and A.L. Lederer, "The effectiveness of strategic information systems planning under environmental uncertainty", Information \& Management 43(4), 2006, pp. 481-501. [27] Hwang, Y.S., M.H. Hwang, and X. Dong, "The relationships among firm size, innovation type, and export performance with regard to time spans", Emerging Markets Finance \& Trade 51(5), 2015, pp. 947-962.

[28] Dooley, K.J., "A complex adaptive systems model of organization change", Nonlinear dynamics, psychology, and life sciences 1(1), 1997, pp. 69-97.

[29] Veliyath, R., and T.C. Srinivasan, "Gestalt Approaches to Assessing Strategic Coalignment: A Conceptual Integration 1", British Journal of Management 6(3), 1995, pp. 205-219.

[30] van de Wetering, R., P. Mikalef, and R. Helms, "Driving organizational sustainability-oriented innovation capabilities: a complex adaptive systems perspective", Current opinion in environmental sustainability 28, 2017, pp. 71-79.

[31] Ortiz de Guinea, A., and J. Webster, "Combining variance and process in information systems research: Hybrid approaches", Information and Organization 27(3), 2017, pp. 144-162.

[32] Roundy, P.T., M. Bradshaw, and B.K. Brockman, "The emergence of entrepreneurial ecosystems: A complex adaptive systems approach", Journal of Business Research 86, 2018, pp. 1-10.

[33] Merali, Y., T. Papadopoulos, and T. Nadkani, "Information systems strategy: Past, present, future?", Journal of Strategic Information Systems 21, 2012, pp. 125-153.

[34] Gelhard, C., S. von Delft, and S.P. Gudergan, "Heterogeneity in dynamic capability configurations: Equifinality and strategic performance", Journal of Business Research 69(11), 2016, pp. 5272-5279.

[35] Fichman, R.G., "Real Options and IT Platform Adoption: Implications for Theory and Practice", Information Systems Research 15(2), 2004, pp. 132154.

[36] Richardson, S.M., W.J. Kettinger, M.S. Banks, and Y. Quintana, "IT and agility in the social enterprise: A case study of st jude children's research 
hospital's 'Cure4Kids' IT-platform for international outreach", Journal of the Association for Information Systems 15(1), 2014, pp. 2.

[37] Tallon, P.P., M. Queiroz, T.R. Coltman, and R. Sharma, "Business process and information technology alignment: construct conceptualization, empirical illustration, and directions for future research", Journal of the Association for Information Systems 17(9), 2016, pp. 563.

[38] Sarcar, M.M.M., K.M. Rao, and K.L. Narayan, Computer aided design and manufacturing, PHI Learning Pvt. Ltd., 2008.

[39] Gunasekaran, A., and Y.Y. Yusuf, “Agile manufacturing: a taxonomy of strategic and technological imperatives", International Journal of Production Research 40(6), 2002, pp. 1357-1385.

[40] Thilak, V.M.M., S.R. Devadasan, M. Vinod, and D.T. Sunil, "Infusing functional agility in pump industry by using Bluetooth enabled mobile phone", International Journal of Business Excellence 14(4), 2018, pp. 499-522.

[41] Vastag, G., J.D. Kasarda, and T. Boone, "Logistical support for manufacturing agility in global markets", International Journal of Operations \& Production Management 14(11), 1994, pp. 73-85.

[42] Huang, C.-Y., and S.Y. Nof, "Enterprise agility: a view from the PRISM lab", International Journal of agile Management systems 1(1), 1999, pp. 51-60.

[43] Seethamraju, R., and J. Seethamraju, "Enterprise systems and business process agility-a case study", 2009 42nd Hawaii International Conference on System Sciences, IEEE (2009), 1-12.

[44] Liu, H., W. Ke, K.K. Wei, and Z. Hua, "The impact of IT capabilities on firm performance: The mediating roles of absorptive capacity and supply chain agility", Decision Support Systems 54(3), 2013, pp. 1452-1462.

[45] Goodhue, D.L., D.Q. Chen, M.C. Boudreau, and J. Cochran, "Addressing business agility challenges with enterprise systems", 2009.

[46] Park, Y., O.A. El Sawy, and P.C. Fiss, "The Role of Business Intelligence and Communication Technologies in Organizational Agility: A Configurational Approach.", Journal of the Association for Information Systems 18(9), 2017, pp. 648-686.

[47] Levinthal, D.A., and J.G. March, "The Myopia of learning", Strategic Management Journal 14, 1993, pp. 95-112.

[48] Dremel, C., M.M. Herterich, J. Wulf, and J. vom Brocke, "Actualizing big data analytics affordances: A revelatory case study", Information \& Management 57(1), 2020, pp. 103121.
[49] Wedel, M., and P.K. Kannan, "Marketing analytics for data-rich environments", Journal of Marketing 80(6), 2016, pp. 97-121.

[50] Torres, R., A. Sidorova, and M.C. Jones, "Enabling firm performance through business intelligence and analytics: A dynamic capabilities perspective", Information \& Management 55(7), 2018, pp. 822-839.

[51] Liu, Y., Y. Liao, and Y. Li, "Capability configuration, ambidexterity and performance: Evidence from service outsourcing sector", International Journal of Production Economics 200, 2018, pp. 343-352.

[52] Brislin, R.W., Translation: Approaches and research, New York, NY, 1976.

[53] Raymond, L., F. Bergeron, A.-M. Croteau, A. Ortiz de Guinea, and S. Uwizeyemungu, "Information technology-enabled explorative learning and competitive performance in industrial service SMEs: a configurational analysis", Journal of Knowledge Management 24(7), 2020, pp. 1625-1651.

[54] Ragin, C.C., Redesigning social inquiry: Fuzzy sets and beyond, University of Chicago Press, Chicago, IL, 2008.

[55] Dul, J., "Identifying single necessary conditions with NCA and fsQCA", Journal of Business Research 69(4), 2016, pp. 1516-1523.

[56] Lee, O.-K., V. Sambamurthy, K.H. Lim, and K.K. Wei, "How does IT ambidexterity impact organizational agility?", Information Systems Research 26(2), 2015, pp. 398-417.

[57] Benbasat, I., and R.W. Zmud, "Empirical research in information systems: The practice or relevance", MIS Quarterly 23(1), 1999, pp. 3-16.

[58] Rosemann, M., and I. Vessey, "Toward improving the relevance of information systems research to practice: the role of applicability checks", MIS Quarterly, 2008, pp. 1-22.

[59] Straub, D., and S. Ang, "Editor's comments: Rigor and relevance in IS research: Redefining the debate and a call for future research", MIS Quarterly, 2011, pp. iii-xi.

[60] van de Wetering, R., P. Mikalef, and R. Helms, Driving organizational sustainability-oriented innovation capabilities: a complex adaptive systems perspective. Current Opinion in Environmental Sustainability, 28, 2017, pp. 71-79. 